\title{
Soluções individuais de abastecimento de água para consumo humano: questões para a vigilância em saúde ambiental
}

\author{
Individual water supply solutions: issues for environmental \\ health surveillance
}

\author{
Julimara de Souza Costa Oliveira ${ }^{1}$, Amanda de Mattos Medeiros ${ }^{1}$, \\ Larissa Gonçalves Castor ${ }^{1}$, Rose Ferraz Carmo², Paula Dias Bevilacqua ${ }^{1}$
}

\begin{abstract}
Resumo
Introdução: Ainda são vários os desafios da Vigilância da Qualidade da Água para Consumo Humano (VQACH) nos municípios, principalmente em relação às soluções alternativas individuais de abastecimento (SAls), as quais podem apresentar ágeis mudanças, especialmente, em cenários de restrição hídrica. Métodos: Analisaram-se os perigos relacionados às SAls cadastradas em município de pequeno porte da Zona da Mata de Minas Gerais, integrando dados relativos à notificação de casos de doença diarreica aguda (DDA). Resultados: Entre setembro de 2013 e janeiro de 2015, foram cadastradas/inspecionadas 584 SAls, das quais $19,7 \%$ localizadas na área urbana e $80,3 \%$ na área rural. Além disso, 92,6\% eram utilizadas para fornecimento de água para consumo humano, atendendo a 2.323 pessoas. Maior proteção e/ou cuidado foram observados na área urbana, assim como maior ocorrência de focos de contaminação (o mais frequente foi o esgoto sanitário). Apenas para área urbana foi identificada correlação estatisticamente significante entre número de SAls e casos notificados de DDA ( $p=0,002)$. Conclusão: Reforça-se a necessidade de investimentos e a priorização de ações da VQACH direcionadas às SAls, já que não são alvos de ações de controle da qualidade da água, bem como o aumento da cobertura da população por serviços de saneamento.
\end{abstract}

Palavras-chave: cadastro; inspeção sanitária; risco sanitário; diarreia; sistemas de informação em saúde.

\begin{abstract}
Introduction: There are still many challenges concerning the Drinking Water Surveillance in the municipalities, mostly related to individual supply solutions (SAI) which may present quick changes, especially in water stress scenarios. Methods: This study analyzed hazards related to SAI recorded in a city at Zona da Mata, Minas Gerais State, integrating data from local report of acute diarrheal disease (DDA). Results: From September/2013 to January/2015, 584 SAI were recorded and inspected; $19.8 \%$ located at urban area and $80.3 \%$ at rural area. Of the total, $92.6 \%$ provided water for human consumption, serving 2,323 people. Higher protection and/or care were observed in urban area, where, on the other hand, there was higher occurrence of sources of contamination (being "wastewater" the most frequent). There was statistically significant correlation between the number of SAI and reported cases of DDA $(p=0.002)$ only for urban area. Conclusion: The data highlight the need for investments and prioritization of Drinking Water Surveillance actions directed to SAI, since they are not subject to water quality control actions; as well as the increase in population coverage by sanitation services.
\end{abstract}

Keywords: census; sanitary inspection; health risk; diarrhea; health information systems.

1Departamento de Veterinária, Universidade Federal de Viçosa (UFV) - Viçosa (MG), Brasil.

${ }^{2}$ Superintendência de Pesquisa, Escola de Saúde Pública do Estado de Minas Gerais (ESP-MG) - Belo Horizonte (MG), Brasil.

Trabalho realizado no município de Viçosa - Viçosa (MG), Brasil.

Endereço para correspondência: Paula Dias Bevilacqua - Departamento de Veterinária, Universidade Federal de Viçosa (UFV), Avenida Peter Henry Rolfs, s/n, Campus Universitário - CEP: 36570-900 - Viçosa (MG), Brasil - Email: paula@ufv.br

Fonte de financiamento: Ministério da Saúde e Ministério da Educação. Edital de Convocação no 28/2012. Projeto de Educação pelo Trabalho para a Saúde/ Vigilância em Saúde PET-Saúde/VS: Produção de Informação e Educação Permanente em Vigilância em Saúde.

Conflito de interesses: nada a declarar. 


\section{INTRODUÇÃO}

No Brasil, a garantia de acesso à água em quantidade suficiente e qualidade compatível com o padrão de potabilidade estabelecido pela legislação vigente é importante atribuição do Sistema Único de Saúde (SUS), operacionalizada pela Vigilância da Qualidade da Água para Consumo Humano (VQACH) ${ }^{1,2}$. O campo de atuação da VQACH compreende as formas de abastecimento de água para consumo humano, coletivas ou individuais, na área urbana ou rural, de gestão pública ou privada, definindo-se três formas de abastecimento: soluções alternativas individuais (SAI), que atendem a domicílios residenciais com uma única família, incluindo seus agregados; soluções alternativas coletivas (SAC), que fornecem água para uso coletivo (com captação subterrânea ou superficial, com ou sem canalização e sem rede de distribuição); e sistema de abastecimento de água (SAA), que é destinado à produção e ao fornecimento coletivo de água potável por meio de rede de distribuiçãa $0^{1,2}$.

Dados do Sistema de Informação sobre Qualidade da Água para Consumo Humano (SISAGUA) mostram que, em 2015, 67,9\% dos municípios brasileiros informaram realizar três das principais ações básicas (cadastro das formas de abastecimento, controle e vigilância da qualidade da água) previstas no Programa Nacional de Vigilância da Qualidade da Água para Consumo Humano (VIGIAGUA): 6,9\% realizavam apenas cadastro; 7\%, cadastro e controle, $12,2 \%$, cadastro e vigilância, e 9,3\% dos municípios não tinham informações registradas no sistema ${ }^{3}$.

Com relação às formas de abastecimento cadastradas, 47,1\% correspondiam a SAI, 40,6\%, a SAC, e 12,3\%, a SAA, abastecendo, respectivamente, 0,73, 3,5 e 71,2\% da população. Entre as SAIs cadastradas, $32,5 \%$ não tinham tratamento da água e 39,5\% não apresentavam informação sobre tratamento no SISAGUA. Em se tratando de SACs e SAA, respectivamente, 64,2 e 14,6\% não tinham tratamento da água. Adicionalmente, as regiões Norte $(50,2 \%)$ e Nordeste $(51,9 \%)$ juntas concentravam mais da metade das SAIs e SACs cadastradas e representavam 38\% dos SAA, mesmo percentual verificado para a região Sudeste (38,1\%). Também é possível verificar, a partir do SISAGUA, que o percentual da população abastecida apenas por SAIs aumenta conforme diminui o tamanho do município, com os maiores percentuais identificados em municípios com menos de 10 mil habitantes $(2 \%)^{3}$. Tais dados demonstram que a implementação das ações da VQACH ainda não é realidade na totalidade dos municípios brasileiros e que a existência de importantes fragilidades no abastecimento de água segura pode ser ilustrada pelos percentuais não desprezíveis de formas de abastecimento de água sem tratamento, sendo as desigualdades inter-regionais e municipais evidentes.

Estudos que avaliam a qualidade da água de soluções de abastecimento localizadas em área rurais (sejam fontes coletivas, abastecendo uma comunidade, sejam fontes individuais, abastecendo domicílios $)^{4-10}$ ou de fontes individuais existentes em áreas urbanas ou periurbana ${ }^{8,11,12}$ estão disponíveis. Porém, são poucas as pesquisas que analisam dados produzidos pelo serviço de VQACH, como: Oliveira ${ }^{9}$, Queiroz et al..$^{13}$ e Aragão ${ }^{14}$, em nível municipal; Vasconcelos et al. ${ }^{15}$, em nível regional; Fernandes et al. ${ }^{16} \mathrm{e}$ Daniel et al. ${ }^{17}$, em nível nacional. No entanto, apenas Oliveira ${ }^{9} \mathrm{e}$ Vasconcelos et al. ${ }^{15}$ avaliam dados referentes às SAIs. O número reduzido de estudos que utilizam dados da VQACH, a exemplo daqueles informados no SISAGUA, pode ser explicado pelo fato de esse sistema de informação não ter seu acesso disponível ao público em geral.

Entre os agravos relacionados à quantidade e à qualidade da água de consumo, destaca-se a doença diarreica, a qual pode apresentar diversas etiologias. A importância desse agravo para a área da saúde pública e a sua aplicação como indicador de saúde e qualidade de vida, uma vez que sua ocorrência está associada a diversos fatores distais ou proximais ao indivíduo, tais como culturais, socioeconômicos, ambientais e de saneamento, nutricionais, idade, entre outros, é destacada por Benicio e Monteiro $^{18} \mathrm{e}$ Teixeira e Heller ${ }^{19}$. Especificamente em relação à água de consumo, seja na dimensão quantitativa e/ou qualitativa, diversos estudos apontam sua associação com a ocorrência de doença diarreica aguda (DDA) $)^{13,18-23} \mathrm{e} o$ impacto das condições de saneamento na redução da morbi-mortalidade por DDA 18,20,21,24. $^{2}$.

Tendo em vista a escassez de informações sobre o abastecimento de água por soluções alternativas individuais, principalmente em áreas urbanas, no Brasil, o presente estudo objetivou analisar eventuais perigos à saúde relacionados às características das SAIs cadastradas, integrando dados relativos à notificação de casos de DDA na área urbana e rural de um município localizado na Zona da Mata mineira. A análise se torna ainda mais oportuna considerando a recente crise hídrica que vem acometendo vários municípios da região Sudeste, implicando, sem dúvida, na busca de outras formas de abastecimento de água, a exemplo das SAIs, as quais usualmente captam água de mananciais subterrâneos (confinados ou não confinados). Tal fato é preocupante, pois a população pode ter como certo que a água subterrânea é protegida de contaminação, levando ao seu consumo sem nenhum tipo de tratamento.

\section{METODOLOGIA}

\section{Cenário de estudo}

O município de Viçosa localiza-se na região da Zona da Mata, Estado de Minas Gerais, Brasil, com população de 72.220 habitantes, dos quais 67.305 residentes na área urbana e 4.915 na área rural ${ }^{25}$. Apresenta cobertura dos serviços básicos de saneamento superior às médias estadual e nacional: $83 \%$ da população é atendida por sistemas de coleta de esgoto, e 98\%, por abastecimento de água. Entretanto, o tratamento de esgoto é praticamente inexistente ${ }^{26}$. 


\section{Caracterização das soluções alternativas individuais de abastecimento de água}

Foram utilizados dados obtidos dos formulários de cadastro e inspeção padronizados pelo Ministério da Saúde (MS) e arquivados no Serviço de Vigilância Epidemiológica da Secretaria Municipal de Saúde (SVE-SMS). Os dados utilizados foram: localização (área urbana ou rural); tipo de manancial (superficial ou subterrâneo); existência de proteção sanitária (tampa, revestimento interno, proteção contra inundação, entre outros); uso da água (consumo humano ou outros usos); número de domicílios e população abastecida; existência de focos de contaminação (esgoto sanitário, atividades agropecuárias, fossas, entre outras); cloração da água; análise bacteriológica da água; tratamento domiciliar (fervura, filtração ou outro); acesso à rede pública de abastecimento; e motivos para utilizar a SAI.

Entre setembro de 2013 e abril de 2014, o cadastro e a inspeção foram realizados pelos agentes de combate às endemias (ACEs), acompanhados de graduandos/as de Enfermagem e Medicina Veterinária do Projeto Produção de Informação e Educação Permanente em Vigilância em Saúde, desenvolvido no âmbito do Programa de Educação pelo Trabalho para a Saúde (PET Saúde) em temas relacionados à Vigilância em Saúde (VS). Entre maio de 2014 e janeiro de 2015, na área urbana, os ACEs, devido ao recrudescimento da dengue no município, realizaram apenas a identificação das SAIs nos domicílios visitados para o controle dessa doença. As atividades de cadastro e de inspeção foram assumidas pela técnica da VQACH do SVE-SMS, em colaboração com os/as graduandos/as do Projeto PET Saúde/VS. Na área rural, o cadastro e a inspeção continuaram a ser realizados pelos ACEs.

Durante o cadastro e a inspeção, o registro das informações envolveu tanto a realização de perguntas ao/à responsável pela SAI como a observação in loco. Para o desenvolvimento das atividades, os ACEs e os/as graduandos/as receberam treinamento sobre qualidade, captação e tratamento da água para consumo humano, bem como sobre o preenchimento do formulário de cadastro e inspeção de SAIs de abastecimento de água.

Os dados foram analisados a partir do cálculo de medidas de frequência, enquanto comparações entre proporções foram realizadas a partir do cálculo do Qui-Quadrado. Para as interpretações, considerou-se o nível de significância de 5\%.

\section{Ocorrência de doença diarreica aguda}

Foram trabalhados dados sobre notificações de casos de DDA obtidos do Sistema de Monitorização de Doença Diarreica Aguda (MDDA) e disponibilizados pelo SVE-SMS. Os dados se referiram aos casos notificados de DDA, segundo o local de residência do paciente, ocorridos em 2013 e 2014.

Foram realizadas análises de correlação entre o número de SAIs cadastradas utilizadas para consumo humano e casos de
DDA notificados segundo o bairro/localidade. Inicialmente, os dados foram testados para normalidade (Teste de Lilliefors) e homocedasticidade (Teste de Bartlett). Como as distribuições dos dados não obedeceram a ambos os critérios, optou-se pela correlação de Spearman (rs). Para as interpretações, considerou-se o nível de significância de $5 \%$.

\section{Questões éticas}

O delineamento do estudo foi aprovado pelo Comitê de Ética em Pesquisa com Seres Humanos da Universidade Federal de Viçosa (Parecer no 479.004/13).

\section{RESULTADOS}

Entre setembro de 2013 e janeiro de 2015, foram identificadas 632 SAIs, das quais $584(92,4 \%)$ foram cadastradas e inspecionadas, $19,7 \%$ na área urbana e $80,3 \%$ na área rural. O uso de SAIs para consumo humano foi maior $(\mathrm{p}<0,0001)$ na área rural $(98,5 \%)$ do que na área urbana (68,6\%), com elevado consumo direto (beber) e preparo de alimentos, seja para área urbana $(93,6 \%)$ ou rural (97\%) (Tabela 1).

Na área urbana, foram identificados 108 domicílios abastecidos por SAIs e, na área rural, 628. Das SAIs localizadas na área urbana, $26,7 \%$ abasteciam mais de um domicílio (dois a quatro), enquanto na área rural, 25,1\% (dois a seis). A população atendida era de $434(0,6 \%)$ pessoas na área urbana e de $1.889(38,4 \%)$ na área rural, correspondendo a 3,2\% da população total do município.

Com relação ao manancial de água, a maioria das SAIs captava manancial subterrâneo (Tabela 1). Alguma proteção sanitária (tampa, revestimento, proteção contra inundação ou acesso de animais) foi identificada em 96,2\% de SAIs na área urbana e em $89 \%$ na área rural.

Menos de 20\% das SAIs apresentaram focos de contaminação. "Esgotos sanitários" (68\%) foi o principal tipo de contaminação identificado na área urbana. Já na área rural, foi identificada maior variedade de tipos de contaminação, dos quais as atividades agropecuárias foram as mais frequentes $(41,5 \%)$ (Tabela 2 ).

$\mathrm{Na}$ maioria das vezes, os responsáveis nunca realizaram análise da água proveniente de SAI, seja na área rural (76\%) ou urbana (59,5\%). A cloração da água na fonte foi identificada tanto na área urbana $(36,7 \%)$ quanto na área rural $(15,6 \%)$. $\mathrm{Na}$ área urbana, em 51,7\% das SAIs, a cloração havia sido feita há mais de seis meses (até o máximo de 180 meses), com média de 14,4 meses (desvio-padrão=32 meses). $\mathrm{Na}$ área rural, para $34,7 \%$ das SAIs, a desinfecção havia sido feita há mais de seis meses, com média igual a 7,4 meses (desvio-padrão=10 meses).

Filtrar a água foi o tratamento domiciliar mais comum, com $74,7 \%$ na área urbana e $77,9 \%$ na rural. No entanto, em 15,2 e 11,4\% de SAIs na área rural e urbana, respectivamente, não era realizado qualquer tratamento domiciliar da água (Tabela 3 ). 
Tabela 1. Uso da água segundo a área de localização das soluções alternativas individuais de abastecimento, em Viçosa, Minas Gerais, em 2013-2015

\begin{tabular}{|c|c|c|c|c|c|c|}
\hline \multirow{2}{*}{ Aspecto } & \multicolumn{2}{|c|}{ Área urbana } & \multicolumn{2}{|c|}{ Área rural } & \multicolumn{2}{|c|}{ Total } \\
\hline & $\mathbf{N}$ & $\%$ & $\mathbf{N}$ & $\%$ & $\mathbf{N}$ & $\%$ \\
\hline \multicolumn{7}{|l|}{ Usos da água } \\
\hline Consumo humano* & 79 & $68,6^{\mathrm{a}}$ & 462 & $98,5^{b}$ & 541 & 92,6 \\
\hline Beber/preparar alimentos & 72 & 93,6 & 448 & 97,0 & 520 & 89,0 \\
\hline Higiene pessoal & 4 & 5,1 & 6 & 1,3 & 10 & 1,7 \\
\hline Somente beber & 1 & 1,3 & 8 & 1,7 & 9 & 1,5 \\
\hline Somente preparar alimentos & 0 & 0,0 & 0 & 0,0 & 0 & 0,0 \\
\hline Outros $^{* *}$ & 36 & 31,4 & 7 & 1,5 & 43 & 7,4 \\
\hline Total $^{* * *}$ & 115 & 100,0 & 469 & 100,0 & 584 & 100,0 \\
\hline \multicolumn{7}{|l|}{ Manancial captado } \\
\hline Poço raso & 81 & 70,4 & 132 & 28,2 & 213 & 36,5 \\
\hline Poço tubular profundo & 22 & 19,1 & 228 & 48,6 & 250 & 42,8 \\
\hline Poço artesiano & 5 & 4,4 & 0 & 0,0 & 5 & 0,8 \\
\hline Mina/nascente/olho d'água & 7 & 6,1 & 108 & 23,0 & 115 & 19,7 \\
\hline Superficial & 0 & 0,0 & 1 & 0,2 & 1 & 0,2 \\
\hline Total & 115 & 100,0 & 469 & 100,0 & 584 & 100,0 \\
\hline
\end{tabular}

*Letras diferentes indicam que há diferença significante no nível de 5\% para o teste de Qui-Quadrado; **Inclui: dessedentação de animais, irrigação, limpeza da casa e lavagem de roupas; ${ }^{* * *}$ Total de usos: consumo humano (todos) e outros

Tabela 2. Focos de contaminação no entorno de 15 metros das soluções alternativas individuais de abastecimento utilizadas para consumo humano, segundo a área, em Viçosa, Minas Gerais, em 2013-2015

\begin{tabular}{|c|c|c|c|c|}
\hline \multirow{2}{*}{ Característica } & \multicolumn{2}{|c|}{ Área urbana } & \multicolumn{2}{|c|}{ Área rural } \\
\hline & $\mathbf{N}$ & $\%$ & $\mathbf{N}$ & $\%$ \\
\hline \multicolumn{5}{|l|}{ Existência de focos de contaminação } \\
\hline $\operatorname{Sim}$ & 25 & 31,6 & 65 & 14,1 \\
\hline Não & 53 & 67,1 & 357 & 77,3 \\
\hline Sem informação & 1 & 1,3 & 40 & 8,6 \\
\hline Total & 79 & 100 & 462 & 100 \\
\hline \multicolumn{5}{|l|}{ Tipos de contaminação } \\
\hline Atividades agropecuárias & 6 & 24,0 & 27 & 41,5 \\
\hline Esgotos sanitários & 17 & 68,0 & 4 & 6,2 \\
\hline Fossas/sumidouros de águas servidas & 0 & 0,0 & 7 & 10,8 \\
\hline Dejetos de animais & 1 & 4,0 & 17 & 26,2 \\
\hline Outros & 0 & 0,0 & 1 & 1,5 \\
\hline Mais de um tipo de contaminação & 1 & 4,0 & 6 & 9,2 \\
\hline Sem informação & 0 & 0,0 & 3 & 4,6 \\
\hline Total & 25 & - & 65 & - \\
\hline
\end{tabular}

Tabela 3. Tratamento domiciliar da água proveniente de soluções alternativas individuais de abastecimento utilizadas para consumo humano, segundo a localização, em Viçosa, Minas Gerais, em 2013-2015

\begin{tabular}{|c|c|c|c|c|}
\hline \multirow{2}{*}{ Tipos de tratamento } & \multicolumn{2}{|c|}{ Área urbana } & \multicolumn{2}{|c|}{ Área rural } \\
\hline & $\mathbf{N}$ & $\%$ & $\mathbf{N}$ & $\%$ \\
\hline Filtração* & 59 & 74,7 & 360 & 77,9 \\
\hline Fervura & 4 & 5,1 & 2 & 0,4 \\
\hline Fervura e filtração & 0 & 0,0 & 6 & 1,3 \\
\hline Vez ou outra filtra & 0 & 0,0 & 2 & 0,4 \\
\hline Outros & 6 & 7,6 & 1 & 0,2 \\
\hline Não realiza tratamento domiciliar & 9 & 11,4 & 70 & 15,2 \\
\hline Sem informação & 1 & 1,3 & 21 & 4,5 \\
\hline Total & 79 & 100,0 & 462 & 100,0 \\
\hline
\end{tabular}

*A filtração se refere ao uso de filtro de barro, em que o elemento filtrante (vela) é de porcelana
O percentual de domicílios com acesso à rede pública de abastecimento foi de $87,3 \%$ na área urbana e 6,1\% na área rural. Os motivos mais frequentes para o uso da SAI foram "custo" (18,8\%) na área urbana e "cheiro/gosto ruim" (17,9\%) na área rural. Outros motivos para o uso da SAI também foram mencionados, dos quais os aspectos que positivaram a água da SAI foram maioria (Tabela 4).

Com relação à notificação de DDA, foram registrados 3.087 casos no período 2013-2014, sendo 1.115 casos em 2013 e $1.972 \mathrm{em} 2014$. Desse total, $96,3 \%$ corresponderam a pacientes residentes na área urbana, e 3,7\%, na área rural.

As análises de correlação entre número de SAIs utilizadas para consumo humano e casos de DDA notificados segundo o 
Tabela 4. Motivos de usuários de soluções alternativas individuais para não usar a água de abastecimento público, segundo a localização, em Viçosa, Minas Gerais, em 2013-2015

\begin{tabular}{lcccccc}
\multirow{2}{*}{\multicolumn{1}{c}{ Motivos }} & \multicolumn{2}{c}{ Área urbana } & & \multicolumn{2}{c}{ Área rural } \\
\cline { 2 - 3 } \cline { 5 - 6 } Cheiro/gosto ruim & $\mathbf{N}$ & $\%$ & & $\mathbf{N}$ & $\%$ \\
Custo & 6 & 8,7 & & 5 & 17,9 \\
Intermitência & 13 & 18,8 & & 3 & 10,7 \\
Outros $^{*}$ & 3 & 4,3 & & 1 & 3,6 \\
Sem informação & 25 & 36,2 & & 8 & 28,6 \\
Total $^{* *}$ & 22 & 31,9 & & 11 & 39,3 \\
\hline
\end{tabular}

*Foram relatados os seguintes motivos: "água do poço é melhor”; "água da cisterna estava atendendo às necessidades"; "não vê necessidade de usar a água do abastecimento público"; "água da SAI é 100\% saudável”; "quando o abastecimento público foi instalado, já existia o poço"; ${ }^{* *}$ Inclui apenas os casos em que o usuário tinha acesso ao abastecimento público de água

bairro/localidade resultaram em uma correlação estatisticamente significante para a área urbana (coeficiente de correlação Spearman $=0,496 ; p=0,002$ ). Não foi observado resultado com significância para a área rural (coeficiente de correlação Spearman $=-0,254 ; \mathrm{p}=0,136$ ).

\section{DISCUSSÃO}

A articulação das atividades de cadastro e inspeção ao trabalho dos ACE foi positiva, pois, como esses profissionais realizam visitas em todos os domicílios (incluindo área urbana e rural), alcançou-se elevada cobertura de cadastro/inspeção. Queiroz et al. ${ }^{27}$ relatam que a estratégia adotada para realizar atividades de identificação, cadastro e inspeção incluiu agentes comunitários de saúde.

Entretanto, com a intensificação do combate à dengue no município, os ACEs, a partir de maio de 2014, passaram apenas a identificar as SAIs nos domicílios visitados, mas o cadastro e a inspeção eram realizados pela técnica do SVE-SMS. Com a transferência dessa profissional para outro setor por causa de mudanças na gestão da saúde municipal, as atividades de VQACH foram interrompidas. Também, a finalização do projeto PET Saúde/VS, em abril de 2015, contribuiu para a descontinuidade das atividades de cadastro/inspeção. A maior cobertura alcançada na área rural foi devido à priorização dessa área entre 2013-2015, pois, em cadastro realizado em 2007, apenas a área urbana foi incluída na atividade ${ }^{28}$.

A necessidade de conformação de equipe mínima e própria de profissionais para as atividades de VQACH, incluindo agentes comunitários de saneamento, foi assinalada por Bevilacqua et al. ${ }^{29}$.

Um maior percentual de SAIs utilizadas para fornecimento de água para consumo humano na área rural era esperado por causa da baixa cobertura ou mesmo da ausência de abastecimento público. Contudo, destaca-se o percentual não desprezível de SAIs na área urbana utilizado para essa finalidade, considerando a elevada (98\%) cobertura urbana desse serviço ${ }^{26}$. A existência de SAIs na área urbana caracteriza importante situação de perigo não só pela inexistência de monitoramento da qualidade da água (o que também ocorre na área rural), mas também pela predominância de poços rasos, mais sujeitos à contaminação, pois o adensamento populacional significa maior concentração de focos de poluição. $\mathrm{Na}$ área rural, o elevado percentual de minas/nascentes sugere vulnerabilidades, pois, dependendo da captação, podem ofertar água de baixa qualidade (contaminação quando a água aflora à superfície do solo).

Estudos demonstram elevados níveis de indicadores de contaminação fecal em fontes de água utilizadas em áreas rurais ${ }^{5-11}$, periurbanas $^{8,28}$ ou urbanas ${ }^{11,12,28}$. Em geral, a contaminação tem origem no manancial devido ao lançamento de efluentes domésticos ou fezes diretamente no solo ou em fossas mal construídas/conservadas, ao acúmulo de resíduos sólidos ("lixões") ${ }^{4,5,10}$ ou de dejetos animais ${ }^{4} \mathrm{em}$ áreas de pastagens, ou durante o trajeto ou transporte da água ao ponto de consumo ${ }^{5,10}$, ou, ainda, por causa da manipulação no domicílio ${ }^{5,8}$. Rocha et al. ${ }^{7}$ propõem abordagem mais sistêmica ao avaliarem a qualidade bacteriológica da água utilizada em duas sub-bacias hidrográficas localizadas no município de Lavras, em Minas Gerais. Apesar de não encontrarem diferenças estatisticamente significantes quanto ao manancial de abastecimento (subterrâneo/superficial), identificaram diferenças segundo os usos e ocupações do solo das sub-bacias, associando maiores riscos de contaminação às atividades antrópicas.

Os achados sobre desinfecção, tratamento domiciliar e realização de análises são relevantes por causa do elevado percentual de uso da água para beber e preparar alimentos. Assim, além de se desconhecer a qualidade da água de consumo, esta é consumida sem tratamento, configurando situação de perigo e possibilidade de ocorrência de agravos à saúde. Outros estudos identificaram percentuais elevados de águas de poços utilizadas para consumo humano sem desinfecção ou tratamento domiciliar, localizados em áreas rurais ${ }^{5-7,9,10}$ e urbanas/periurbanas ${ }^{28}$, ou, ainda, percentuais elevados de amostras de água provenientes de soluções coletivas ou individuais de abastecimento com teor de cloro residual livre abaixo do determinado pela legislação ${ }^{11,15}$. A análise da água também não foi preocupação da maioria dos consumidores de água proveniente de poços em área rural ${ }^{7,28}$.

A ausência de verificação da qualidade e/ou de tratamento da água de SAIs, normalmente poços e nascentes, pode estar associada à representação positiva que a população normalmente tem sobre essas águas. Representações sociais sobre a água de consumo humano são, em geral, elaboradas a partir dos sentidos, sobretudo sabor e visão, conformando um padrão de potabilidade que parece ser sintetizado pela "pureza" da água ${ }^{30}$. Assim, a água adequada para consumo é caracterizada pela população a partir de parâmetros físicos, como cor, gosto, odor e material em suspensão $0^{7,28,30-32}$. Ribeiro e Galizoni ${ }^{33}$ referem-se 
ao fato de que águas de nascentes, minas preservadas, com mato em volta, ou que surgem sobre pedras, possuem sentido daquilo que é puro e intocado, nascido da terra, guardando uma boa qualidade. Assim, o "aspecto" usualmente adequado das águas provenientes de mananciais subterrâneos implica em "confiança" e, consequentemente, na dispensa da sua análise ou mesmo do seu tratamento ${ }^{6}$.

O elevado percentual de SAIs apresentando algum tipo de proteção sanitária deve ser interpretado com cautela, pois a existência de proteção não garante ausência de contaminação do manancial: ou a proteção sanitária pode não ser adequada ao tipo de captação existente, ou a contaminação pode ocorrer no transporte da água ao consumo. Amaral et al. ${ }^{6}$ identificaram fontes de água utilizadas para consumo humano na área rural sem fatores de proteção considerados importantes (como tampa, revestimento interno e/ou localização em cota mais alta no terreno). Em poços localizados em áreas urbanas, também foram identificadas fragilidades em relação à proteçãa ${ }^{12,28}$. Segundo Kravitz et al. ${ }^{5}$, a proteção adequada das fontes melhora a qualidade da água, prevenindo a contaminação por Escherichia coli, especialmente quando a desinfecção não é realizada. Entretanto, é fundamental que as fontes de água sejam periodicamente inspecionadas para verificação da integridade das proteções existentes e que sejam realizadas manutenções, quando necessárias.

A preferência pela água de SAIs em detrimento do abastecimento público foi explorada por Soares ${ }^{28}$, que encontrou, em relatos de usuários, uma "defesa" para o uso dessa forma de abastecimento. Segundo a autora, "o poço/mina e a água dele proveniente não são meros elementos físicos do ambiente, são parte integrante da casa, da família, fazem parte da história de vida das pessoas; conectam e referenciam épocas (infância, juventude) e momentos (construção da casa, casamento), são elementos de referência e de construção da memória dos indivíduos". Assim, a defesa do poço/mina e da água é também a defesa da própria identidade, ou seja, o resgate das origens.

$\mathrm{Na}$ área urbana, essa preferência deve ser considerada tanto pelo responsável pelo abastecimento quanto pelo setor saúde. No caso do primeiro, a rejeição pode estar relacionada com a percepção de que a água (ou o serviço) não é boa (bom) devido a características indesejáveis, como gosto ou odor ruins, presença de cor ou material em suspensão. No caso do setor saúde, importa reconhecer que a forma como a população percebe/lida com as características organolépticas da água pode influenciar a escolha da água consumida, direcionando a opção por fontes não seguras ${ }^{30}$.

Com relação à área rural, como há ausência do serviço público, não se trata de opção pelo uso de SAIs, mas de imposição, cabendo a reflexão sobre a universalização do acesso aos serviços de saneamento, definida como princípio fundamental pela Lei $\mathrm{n}^{0} 11.445^{34}$, e o direito humano de acesso à água segura, conforme declaração da Organização das Nações Unidas ${ }^{35}$ e explicitado nos Objetivos do Desenvolvimento Sustentável ${ }^{36}$. Apesar da determinação jurídica, no caso do saneamento, a efetivação desse princípio depende das características dos arranjos existentes para a oferta do serviço, ou seja, "[...] a garantia legal para a universalização deverá estar assegurada nos marcos de cada concessão, mediante cláusulas e metas de expansão e de atendimento previstas nos contratos de concessão e de programa" (p. 549) ${ }^{37}$. Segundo dados da Pesquisa Nacional por Amostra de Domicílios, apenas $33,4 \%$ dos domicílios brasileiros nas áreas rurais estão ligados a redes de abastecimento de água (com ou sem canalização interna) e, em Minas Gerais, apenas 23\% $\%^{38}$. Assim, a área rural, historicamente negligenciada em termos de cobertura dos serviços de saneamento, pode continuar a ser excluída se não estiverem previstas ampliações de cobertura, bem como o uso de tecnologias adequadas e de fácil assimilação pela população.

Para Galvão ${ }^{37}$, na definição de critérios de universalização, não devem ser considerados apenas aspectos técnicos, mas também variáveis sociais e econômicas, relacionadas tanto à implantação quanto à sustentabilidade dos serviços. Além disso, complementa o autor, no caso do abastecimento de água, a qualidade e a continuidade do fornecimento são fundamentais, pois, quando não garantidas, podem expor a população a riscos, às vezes, maiores do que o anteriormente existente.

Segundo estudo realizado pelo Ministério das Cidades ${ }^{39}$, para atingir as metas projetadas para a área rural, as quais incluem mais do que ampliação da cobertura dos domicílios abastecidos por rede de distribuição e por poço ou nascente com canalização interna, seriam necessários investimentos da ordem de $\mathrm{R} \$ 7,3$ bilhões entre 2013 e 2033. Apesar de evidências do aumento do gasto público em ações de saneamento, os investimentos ainda são aquém do necessário, e as desigualdades regionais, intrarregionais e relativas ao componente (abastecimento de água, esgotamento sanitários, resíduos sólidos e drenagem) ainda persistem ${ }^{40}$.

Importante salientar que, diante do cenário atual de crise hídrica, agravado a partir de 2014, na região Sudeste, espera-se aumento da perfuração de poços e, consequentemente, da utilização de SAIs como alternativa à interrupção do abastecimento público de água, o que já vem sendo verificado em outros municípios brasileiros ${ }^{41}$, com registro de aumento de 30 a $40 \%$ na perfuração de poços ${ }^{42}$. Esse fato deve ser motivo de preocupação para a VQACH, pois, além do aumento da demanda por ações relacionadas a esse serviço, tem-se aumento da exposição de consumidores, principalmente na área urbana onde as ações de incentivo à redução de consumo de água em época de crise hídrica, como racionamento e rodízio, são maiores.

A ausência de correlação entre casos notificados de DDA e número de SAIs na área rural pode ter sido influenciada pelo reduzido número de registros $(3,7 \%)$ de DDA nessa área. 
A notificação de casos resulta de vários fatores, como o acesso aos serviços de saúde, o que sabidamente é mais precário na área rural, e o fato de as pessoas minimizarem a gravidade da DDA, não buscando atendimento médico. A fragilidade dos registros de DDA também deve ser considerada, pois, para a maioria dos casos notificados, o endereço dos pacientes não constava ou estava incompleto, dificultando a análise integrada dos bancos de dados (MDDA e cadastro de SAIs).

$\mathrm{O}$ resultado encontrado para a área urbana reflete o que diferentes estudos já demonstram sobre a associação da água (em quantidade e qualidade) com a ocorrência de diarreia ${ }^{13,18-23}$. Assim, ainda que caibam as mesmas limitações metodológicas assinaladas anteriormente, os resultados sugerem a necessidade de ações específicas da VQACH considerando as SAIs.

\section{CONCLUSÕES}

As atividades de identificação/cadastro/inspeção das formas de abastecimento de água são fundamentais para a orientação das demais ações da VQACH. Tais atividades devem ser frequentemente atualizadas, uma vez que as fontes de água utilizadas para consumo humano podem apresentar ágeis reconfigurações, principalmente em se tratando das SAIs. Assim, a existência de recursos humanos qualificados é essencial, sendo imprescindível a conformação de equipe mínima e própria de profissionais para execução das atividades de VQACH.

Foi possível verificar que o número de SAIs utilizadas para fornecimento de água para consumo humano existente no município é significativo, atendendo à população não desprezível. Adicionalmente, a inspeção apontou diferentes fragilidades, indicando a exposição dos/as consumidores à água não segura. Uma vez que esse tipo de abastecimento não é alvo de atividades sistemáticas de avaliação da qualidade da água, reforça-se a necessidade de investimentos e a priorização de ações da VQACH direcionadas às SAIs.

O trabalho também aponta a importância das atividades de notificação de agravos e o adequado registro de dados e atualização dos sistemas de informação da saúde, de forma a permitir análises integradas de dados para melhor apoiar as ações de VQACH.

Finalmente, os resultados também sinalizam para a necessidade de investimentos do setor saneamento em termos de ampliação da cobertura do abastecimento de água na área rural, ainda que de forma adequada/adaptada à realidade, mas cumprindo os princípios de universalidade e equidade e garantindo o direito humano de acesso à água segura.

\section{REFERÊNCIAS}

1. Brasil. Portaria $\mathrm{n}^{\circ} 2.914$, de 12 de dezembro de 2011. Dispõe sobre os procedimentos de controle e de vigilância da qualidade da água para consumo humano e seu padrão de potabilidade. Diário Oficial da União, Brasília, 14 de dezembro de 2012.

2. Brasil. Ministério da Saúde. Secretaria de Vigilância em Saúde. Programa Nacional de Vigilância em Saúde Ambiental relacionada à qualidade da água para consumo humano. Brasília: Ministério da Saúde; 2005. (Série C. Projetos, Programas e Relatórios).

3. Brasil. Ministério da Saúde. Sistema de Informação de Vigilância da Qualidade da Água para Consumo Humano (Sisagua). Brasília: Ministério da Saúde; 2016

4. Stukel TA, Greenberg ER, Dain BJ, Reed FC, Jacobs NJ. Longitudinal study of rainfall and coliform contamination in small community drinking water supplies. Environ Sci Technol. 1990;24(4):571-5. http://dx.doi.org/10.1021/ es00074a610.

5. Kravitz JD, Nyaphisi M, Mandel R, Petersen E. Quantitative bacterial examination of domestic water supplies in the Lesotho Highlands: water quality, sanitation, and village health. Bull World Health Organ. 1999;77(10):829-36. PMid:10593031.

6. Amaral LA, Nader A Fo, Rossi OD Jr, Ferreira FLA, Barros LSS. Água de consumo humano como fator de risco à saúde em propriedades rurais. Rev Saude Publica. 2003;37(4):510-4. PMid:12937713. http://dx.doi.org/10.1590/ S0034-89102003000400017.

7. Rocha CMBM, Rodrigues LS, Costa CC, Oliveira PR, Silva IJ, Jesus EFM, et al. Avaliação da qualidade da água e percepção higiênico-sanitária na área rural de Lavras, Minas Gerais, Brasil, 1999-2000. Cad Saude
Publica. 2006;22(9):1967-78. PMid:16917594. http://dx.doi.org/10.1590/ S0102-311X2006000900028.

8. Colvara JG, Lima AS, Silva WP. Avaliação da contaminação de água subterrânea em poços artesianos no sul do Rio Grande do Sul. Braz J Food Technol. 2009;2:11-4

9. Oliveira KAO. Qualidade da água para consumo humano em solução alternativa de abastecimento no município do Cabo de Santo Agostinho, Pernambuco [monografia]. Recife: Centro de Pesquisa Aggeu Magalhães, Fundação Oswaldo Cruz; 2011.

10. Satake FM, Assunção AW, Lopes LG, Amaral LA. Qualidade da água em propriedades rurais situadas na bacia hidrográfica do Córrego Rico, Jaboticabal-SP. Ars Veterinaria. 2012;28(1):48-55.

11. Oliveira KSR. Vigilância e controle da qualidade da água para consumo humano no distrito de Camela, Ipojuca-PE [monografia]. Recife: Universidade Federal Rural do Semi-Árido; 2008

12. Silva RCA, Araújo TM. Qualidade da água do manancial subterrâneo em áreas urbanas de Feira de Santana (BA). Cien Saude Colet. 2003;8(4):1019 28. http://dx.doi.org/10.1590/S1413-81232003000400023.

13. Queiroz JTM, Heller L, Silva SR. Análise da correlação de ocorrência da doença diarreica aguda com a qualidade da água para consumo humano no município de Vitória-ES. Saude Soc. 2009;18(3):479-89. http://dx.doi. org/10.1590/S0104-12902009000300012.

14. Aragão AAV. Avaliação do Programa de Vigilância da Qualidade da Água para Consumo Humano no município de Buíque-PE [dissertação]. Recife: Centro de Pesquisa Aggeu Magalhães, Fundação Oswaldo Cruz; 2012. 
15. Vasconcelos CH, Andrade RC, Bonfim CV, Resende RMS, Queiroz FB, Daniel MHB, et al. Surveillance of the drinking water quality din the Legal Amazon: analysis of vulnerable areas. Cad Saude Colet. 2016;24(1):14-20. http://dx.doi.org/10.1590/1414-462X201500040142.

16. Fernandes No ML, Tambellini AT, Daniel MHB, Bezerra NR. Vigilância da qualidade da água para consumo humano em municípios acima de 100.000 habitantes: avaliação do desenvolvimento de ações mínimas e desafios para sua efetiva implementação. In: Anais do XXIV Congresso Brasileiro de Engenharia Sanitária e Ambiental; 2007; Belo Horizonte. São Paulo: ABESP; 2007. p. 1-8.

17. Daniel MHB, Mendonça JC, Cabral AR. Estruturação das secretarias municipais de saúde para executar a Vigilância da Qualidade da Água para Consumo Humano em cumprimento à Portaria MS n. ${ }^{\circ}$ 518/2004. In: Anais do XXV Congresso Brasileiro de Engenharia Sanitária e Ambiental; 2009; Recife. São Paulo: ABESP; 2009. p. 1-14.

18. Benicio MHA, Monteiro CA. Tendência secular da doença diarreica na infância na cidade de São Paulo (1984-1996). Rev Saude Publica. 2000;34(6 Supl 6):83-90. PMid:11428203. http://dx.doi.org/10.1590/S003489102000000700011 .

19. Teixeira JC, Heller L. Fatores ambientais associados à diarreia infantil em áreas de assentamento subnormal em Juiz de Fora, Minas Gerais. Rev Bras Saude Mater Infant. 2005;5(4):449-55. http://dx.doi.org/10.1590/S151938292005000400008 .

20. Esrey SA, Habicht JP. Epidemiologic evidence for health benefits from improved water and sanitation in developing countries. Epidemiol Rev. 1986;8(1):117-28. PMid:3533581. http://dx.doi.org/10.1093/oxfordjournals. epirev.a036290.

21. Gross R, Schell B, Molina MC, Leão MA, Strack U. impact of improvement of water supply and sanitation facilities on diarrhea and intestinal parasites: a Brazilian experience with children in two low-income urban communities. Rev Saude Publica. 1989;23(3):214-20. PMid:2617116. http://dx.doi. org/10.1590/S0034-89101989000300006.

22. Kolsky PJ. Diarrhoeal disease: current concepts and future challenges. water, sanitation and diarrhea: the limits of understanding. Trans R Soc Trop Med Hyg. 1993;87(3 Supl):43-6. PMid:8108850. http://dx.doi.org/10.1016/00359203(93)90537-Z

23. Fewtrell L, Kaufmann RB, Kay D, Enanoria W, Haller L, Colford JM Jr. Water, sanitation, and hygiene interventions to reduce diarrhea in less developed countries: a systematic review and meta-analysis. Lancet Infect Dis. 2005;5(1):42-52. PMid:15620560. http://dx.doi.org/10.1016/S14733099(04)01253-8.

24. Briscoe J, Feachem RG, Rahaman MM. Evaluating health impact, water supply, sanitation and hygiene education. Ottawa: International Development Research Center; 1986.

25. Instituto Brasileiro de Geografia e Estatística. Cidades@ [Internet].2016 [citado em 2016 jul 16]. Disponível em: http://www.cidades.ibge.gov.br/ xtras/home.php

26. Serviço Autônomo de Água e Esgoto. Sistema de água [Internet]. 2016 [citado em 2016 jul 16]. Disponível em: www.saaevicosa.com.br

27. Queiroz ACL, Cardoso LSM, Silva SCF, Heller L, Cairncross S. Programa Nacional de Vigilância em Saúde Ambiental relacionada à Qualidade da Água para Consumo Humano (VIGIAGUA): lacunas entre a formulação do programa e sua implantação na instância municipal. Saude Soc. 2012;21(2):465-78. http://dx.doi.org/10.1590/S0104-12902012000200019.
28. Soares ACC. Abastecimento e consumo de água por soluções individuais em Viçosa-MG: Identificação de perigos e percepção da população consumidora [dissertação]. Viçosa: Departamento de Veterinária, Universidade Federal de Viçosa; 2010.

29. Bevilacqua PD, Carmo RF, Melo CM, Bastos RKX, Oliveira DC, Soares ACC, et al. Vigilância da qualidade da água para consumo humano no âmbito municipal: contornos, desafios e possibilidades. Saude Soc. 2014;23(2):467-83. http://dx.doi.org/10.1590/S0104-12902014000200009.

30. Carmo RF, Bevilacqua PD, Barletto M. Social representations of drinking water: subsidies for water quality surveillance programmes. J Water Health. 2015;13(3):671-9. PMid:26322753. http://dx.doi.org/10.2166/wh.2015.171.

31. Doria MF. Factors influencing public perception of drinking water quality. Water Policy. 2010;12(1):1-19. http://dx.doi.org/10.2166/wp.2009.051.

32. Silva SR, Heller L, Valadares JC, Cairncross S. Relationship (or its lack) between population and a water supply company: a study of user's perception in Vitória (ES) Brazil. J Water Health. 2010;8(4):764-78. PMid:20705987. http://dx.doi.org/10.2166/wh.2010.067.

33. Ribeiro EM, Galizoni FM. Água, população rural e políticas de gestão: o caso do vale do Jequitinhonha, Minas Gerais. Ambiente \& Sociedade. 2003;5(2):129-46. http://dx.doi.org/10.1590/S1414-753X2003000200008.

34. Brasil. Lei ${ }^{\circ} 11.445$, de 5 de janeiro de 2007. Estabelece diretrizes nacionais para o saneamento básico. Diário Oficial da União, Brasília, 8 de janeiro de 2007.

35. United Nations. General Assembly. Resolution 64/292 (A/RES/64/292) adopted by the General Assembly on 28 July 2010. The human right to water and sanitation. General Assembly, Geneva, 28 de julho de 2010

36. Sachs J. From millennium development goals to sustainable development goals. Lancet. 2012;379(9832):2206-11. PMid:22682467. http://dx.doi. org/10.1016/S0140-6736(12)60685-0.

37. Galvão Jr AC. Desafios para a universalização dos serviços de água e esgoto no Brasil. Rev Panam Salud Publica. 2009;25(6):548-56. PMid:19695151.

38. Instituto Brasileiro de Geografia e Estatística. Pesquisa nacional por amostra de domicílios [Internet]. 2014 [citado em 2016 jul 12]. Disponível em: http://www.ibge.gov.br/home/estatistica/populacao/trabalhoerendimento/ pnad2014/

39. Brasil. Ministério das Cidades. Plano Nacional de Saneamento Básico (PLANSAB): versão para apreciação do CNS, CONAMA, CNRH e CONCIDADES. Brasília: Ministério das Cidades; 2013. 172 p.

40. Borja PC. Política pública de saneamento básico: uma análise da recente experiência brasileira. Saude Soc. 2014;23(2):432-47. http://dx.doi. org/10.1590/S0104-12902014000200007.

41. Bertolo R, Hirata R, Conicelli B, Simonato M, Pinhatti A, Fernandes A. Água subterrânea para abastecimento público na Região Metropolitana de São Paulo: é possível utilizá-la em larga escala? Rev DAE. 2015;199(199):617. http://dx.doi.org/10.4322/dae.2014.148.

42. Straci L. Setor em movimento. Rev Agua e Meio Ambiente Subterraneo. 2015;7(45):10.

Recebido em: Mar. 10, 2017 Aprovado em: Jun. 08, 2017 